\title{
Simulation on Low Velocity Impacted Damage of Sandwich Composite with Finite Element Analysis
}

\author{
Yanpeng Feng, ${ }^{1, *}$ Li Chen ${ }^{2}$, Chun Wang ${ }^{1,3}$, Haijun Tang ${ }^{1,3}$, Chunguang Li1 ${ }^{1,3}$, Xiaoming Ma ${ }^{1}$, Yang Jiao ${ }^{1}$ \\ ${ }^{1}$ China Academy of Civil Aviation Science and Technology \\ ${ }^{2}$ China Special Equipment Inspection and Research Institute \\ ${ }^{3}$ Engineering and Technical Research of Civil Aviation Safety Analysis and Prevention of Beijing \\ ${ }^{*}$ Corresponding author
}

\begin{abstract}
A finite element tool was used to simulate the structural and damage response of honeycomb sandwich composites subjected to low-velocity impact, under different energy. Damage evolution such as composite skins failure, and collapse of honeycomb core was assessment by different damage models. And interlaminar damage was assessed by cohesive laws. The nonlinear behavior of honeycomb was simulated by a crushable foam plasticity model. Results of finite element simulation were compared with falling weight impact test on honeycomb sandwich panels consisting of carbon fiber preparation facesheets bonded to paper honeycomb structure foam. Good agreement and Acceptable error was obtained between predictions and experiments in terms of force histories, force-displacement curves and dissipated energy. The proposed model was also capable of simulating correctly nature and size of impact damage, capturing the features of delimitaztions between core and different layers.
\end{abstract}

Keywords-delamination; sandwich composite; Impact Damage; Finite element analysis (FEM)

\section{INTRODUCTION}

Sandwich composites consisting of two laminated facesheets and a low density core material have been increasingly used in aircraft structures [1]. Because of their high specific strength and weight rate, fine environmental resistance. For example, sandwich composite configurations are frequently used in wing shells, rudder and radome, and are under consideration for use in other potential loading carrying field. As the process of manufacturing, transport, installation and service, the sandwich composites susceptibility to damage caused by foreign object impact events. Damage assessment and prediction of sandwich composites by low velocity impact, had be well know for many years [2][3], and is significant attention by civil aviation and military aviation.

Damage of sandwich composite contains delaminating; fiber fracture; face-core deboning and core crushing that initiate at different stages, and grow and interact at different rates under increasing impact loading. So model of damage predict method must taking into account all these factors. But too many calculate resource and too much compute time are unreality and difficult to realize. It was recognized that the problem could be simplified by making some assumptions about the nature of the impact damage.

Different simulation models were proposed by researchers in recent decades, to illustrate and analysis the monolithic composite laminates under low-velocity impact [5]. Advance and Progressive damage models have been extensively proposed to coordinate the output of failure mechanisms, inelasticity properties and dynamic damage evolutions [6][7].

Hashin criteria was wildly used for fiber enhanced composite factsheets [8], but the fault criterion for different models was progressive by different researchers. Typical damage models combine of failure methods, used to identify the initiation of damage, material degradation strategies and energy balance treatment due to damage evaluation [9]. In particular, stiffness degradation schemes developed in the framework of continuum damage mechanics (CDMs). Cohesive zone models (CZM) used to predict the growth of various types of cracks are reviewed in this article with a special focus on impact problems [4]. The crushing behaviors of composites laminates tubes had been numerically simulated using finite elements, by cohesive elements to allow for delaminating, by Palanivelu et al [10].

The aim of current research is to develop an analytical method including different impact damage models, as using Hashin criteria with linear softening for damage evolution of composite face sheets. Cohesive elements with zero thick for bonding contact of surface and core layer, and using crushable plastic foam layer for core layers. drop and FE results for plate deflections and strains are compared to experimental measurement to evaluate their accuracy.

\section{EXPERIMENTAL METHODS}

The composite material is IM7/8552 supplied by, as a preimpregnated tape of epoxy resin (8552) reinforced by continuous, orthogonally complied factsheet, with paper honeycomb core. Sandwich panels were cut to $350 \mathrm{~mm}$ wide and $670 \mathrm{~mm}$ long. Individual plies of factsheet are about 0.5 $\mathrm{mm}$ and core is $5 \mathrm{~mm}$ in thickness.

Impact tests were conducted using an instrumented dropweight testing machine equipped with a $2.34 \mathrm{~kg}$ impactor supplied with a hemispherically ended rod of $12.5 \mathrm{~mm}$ in diameter, according to the standard of. The velocity of the impactor immediately before and after the impact was obtained by an infra-red sensor, while the contact force between impactor and specimen was measured by means of a semiconductor strain-gage bridge bonded to the impactor rod. During impact testing, the sandwich panels were simply supported on a steel plate with a rectangular opening $45 \mathrm{~mm}$ 
wide and $67.5 \mathrm{~mm}$ long, and subjected to impact with energies ranging between approximately $1 \mathrm{~J}$ and $9 \mathrm{~J}$, obtained by varying the drop height of the impactor.

\section{Modeling OF SANDwich Panels}

A full 3D finite element model of $350 \mathrm{~mm}$ wide and 670 $\mathrm{mm}$ length sandwich panels were constructed in ABAQUS/Explicit using continuous shell element for factsheet and solid element for honeycomb core, and cohesive element for simulation of the interfaces between core and factsheets. The impactor was modelled as a rigid hemispherical body using R3D4 rigid elements. the mass of impactor with $2.34 \mathrm{~kg}$ was imposed using a reference point constraint by center of mess. The supporting plate was simulated by displacement constraint of boundary.

\section{A. Fiber Reinforced Composite Panels}

Energy-based accumulated damage models were adopted to prediction the initiation and propagation of composite factsheets, and the process of post damage evaluation was simulated by materials stiffness degradation, that proposed by Hashin et al [8]. The following function is the stiffness matrix.

$$
C_{d}=\frac{1}{D}\left[\begin{array}{ccc}
\left(1-d_{f}\right) E_{1} & \left(1-d_{f}\right)\left(1-d_{m}\right) v_{21} E_{1} & 0 \\
\left(1-d_{f}\right)\left(1-d_{m}\right) v_{12} E_{2} & \left(1-d_{m}\right) E_{2} & 0 \\
0 & 0 & \left(1-d_{n}\right) G D
\end{array}\right]
$$

In which, $\mathrm{d}_{f}$ is the damage factor of fiber broken, $\mathrm{dm}$ and $\mathrm{d}_{n}$ are damage factors of resin matrix and shear failure, respectively. $E_{1}$ is young modulus of fiber direction and $E_{2}$ is young modulus of direction perpendicular to fiber. $G$ was shear modulus, and $\mathrm{v}_{12}$ and $\mathrm{v}_{21}$ are poisson ratio.

$$
D=1-\left(1-d_{f}\right)\left(1-d_{m}\right)
$$

So node stress was illustrated with function 2, that is node strain.

$$
\sigma=C_{d} \varepsilon
$$

The composite failure criteria proposed by Hashin include four failure modes: fiber tensile fracture, fiber compress fracture, matrix cracking, matrix crushing. Many modifications were made to predict the failure of tap plies, woven ones et al. Finite element model used for simulation of sandwich composite panel and with rigid impacted. One quarter of panel and impacted were establishment to decrease the computational resources.

Fiber tensile failure:

$$
F_{f}^{t}=\left(\frac{\hat{\sigma}_{11}}{X^{T}}\right)^{2}+\alpha\left(\frac{\hat{\tau}_{12}}{S^{L}}\right)^{2}
$$

Fiber compress fracture:

$$
F_{f}^{c}=\left(\frac{\sigma_{11}}{X^{c}}\right)^{2}
$$

Matrix breakage:

$$
F_{m}^{t}=\left(\frac{\hat{\sigma}_{22}}{Y^{T}}\right)^{2}+\left(\frac{\hat{\tau}_{12}}{S^{L}}\right)^{2}
$$

\begin{tabular}{|c|c|}
\hline Property & Value \\
\hline Longitudinal stiffness, $E_{11}(\mathrm{GPa})$ & 109 \\
\hline Transverse stiffness, $E_{22}(\mathrm{GPa})$ & 8.82 \\
\hline Out-of-plane stiffness, $E_{33}(\mathrm{GPa})$ & 8.82 \\
\hline Poisson's ratio, $\mathrm{v}_{12}$ & 0.342 \\
\hline Poisson's ratio, $\mathrm{v}_{13}$ & 0.342 \\
\hline Poisson's ratio, $\mathrm{v}_{23}$ & 0.52 \\
\hline Shear modulus, $\mathrm{G}_{12}(\mathrm{GPa})$ & 4.32 \\
\hline Shear modulus, $\mathrm{G}_{23}(\mathrm{GPa})$ & 2.2 \\
\hline Longitudinal tensile strength, & 1132 \\
\hline Longitudinal compressive strength, & 1132 \\
\hline Transverse tensile strength, & 50 \\
\hline Transverse compressive strength & 150 \\
\hline Longitudinal shear strength & 50 \\
\hline Transverse shear strength & 75 \\
\hline Density, $\rho\left(\mathrm{kg} / \mathrm{m}^{3}\right)$ & 1532 \\
\hline
\end{tabular}

Matrix crushing:

$$
F_{m}^{c}=\left(\frac{\hat{\sigma}_{22}}{2 S^{T}}\right)^{2}+\left[\left(\frac{Y^{C}}{2 S^{T}}\right)^{2}-1\right] \frac{\hat{\sigma}_{22}}{Y^{C}}+\left(\frac{\hat{\tau}_{12}}{S^{L}}\right)^{2}
$$

TABLE I. DESCRIPTION OF THE PROPERTIES OF SKIN MATERIAL BEING USEDTABLE TYPE STYLES

An 8-node quadrilateral in-plane general-purpose continuum shell was used for the simulated of fiber reinforced composite panels. The selected mesh consisted of 55,860 elements on the sandwich panel.

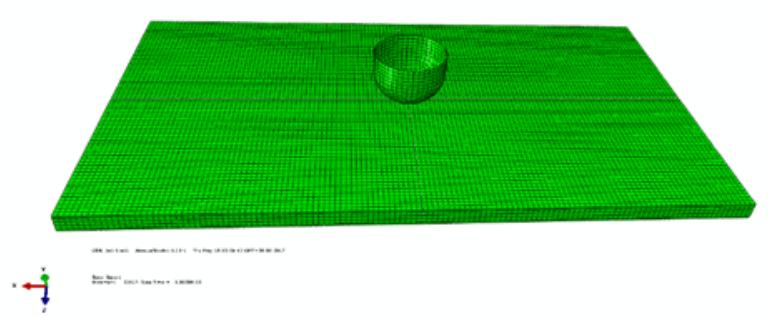

FIGURE I. FE MODEL OF HONEYCOMB SANDWICH COMPOSITE PANEL WITH RIGID IMPACTOR 


\section{B. Honeycomb Core Panel}

The linear hexahedron element type C3D8R was used to simulate the deformation behavior of core panel. The properties of foam material were listed as following. Total 7215 elements were uesd.

TABLE II. DESCRIPTION OF THE PROPERTIES OF FOAM MATERIAL BEING USED

\begin{tabular}{|c|c|}
\hline Property & Value \\
\hline Density $\left(\mathrm{Kg} / \mathrm{m}^{3}\right)$ & 97 \\
\hline Elastic modulus (MPa) & 92 \\
\hline Poisson's ratio & 0.3 \\
\hline Hydrostatic yield stress ratio & 0.07 \\
\hline Compress Yield stress ratio & 0.2 \\
\hline
\end{tabular}

\section{Intralaminar Damage Models}

Delaminating between fiber reinforced surface panels and honeycomb core were simulated by interface cohesive elements. Different cohesive zone models were reviewed by S. Abrate[4], and presented results shown an acceptable accuracy could be obtained. However, stability of solution process is difficult to guarantee without refined mesh.

Defined by a traction-separation constitutive law consisting of an initial linear elastic stage until a damage initiation condition is satisfied (a stress-based quadratic interaction criterion was used in the calculations), followed by a linear softening phase that simulates the progressive decohesion of the interface with increasing damage (Fig. 2). Complete fracture of the interface is assumed to occur when cohesive tractions vanish at the end of the degradation phase. The evolution of damage was monitored by a damage indicator $\mathrm{d}$, ranging from the value of 0 for the undamaged interface to the value of 1 corresponding to complete decohesion of the interface.
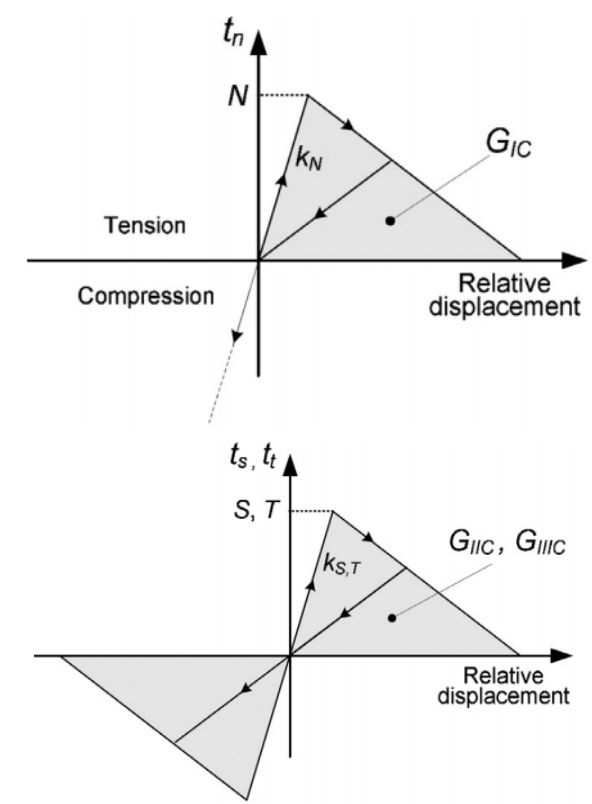

FIGURE II. RELATIVE DISPLACEMENT AND TENSION STRESS OF INTERFACE COHESIVE ELEMENT
The following function was interface delaminations criterion:

$$
\left(\frac{\mathrm{G}_{\mathrm{I}}}{\mathrm{G}_{\text {Ic }}}\right)^{2}+\left(\frac{\mathrm{G}_{\text {II }}}{\mathrm{G}_{\text {IIc }}}\right)^{2}+\left(\frac{\mathrm{G}_{\text {III }}}{\mathrm{G}_{\text {IIIc }}}\right)^{2}=1
$$

That provided a good match with experimental result, and was used to model delamination damages under impacted loading. The properties of interface cohesive elements used were list in following, which based by experiment and related articles[11].

\section{TABLE III. DESCRIPTION OF THE PROPERTIES OF INTERFACE} COHESIVE ELEMENTS BEING USED

\begin{tabular}{|c|c|}
\hline Property & Value \\
\hline Density (Kg/m3) & 75 \\
\hline Elastic modulus (MPa) & 92 \\
\hline Poisson's ratio & 0.3 \\
\hline Shear modulus (MPa) & 29 \\
\hline Tensile strength (MPa) & 2.8 \\
\hline Compressive strength (MPa) & 1.5 \\
\hline Shear strength (MPa) & 1.3 \\
\hline Elongation at break (\%) & 3 \\
\hline
\end{tabular}

\section{Simulation of Sandwich Panels}

To illustrate the result directly, the mirror image of original model along $x-y$ plane were shown in fig 3 , and ally the following images were treated by mirror methods two. After impacted, the stress contour and stress-field status were shown in fig 3 . The impact energy was $5 \mathrm{~J}$, and diameter of impactor was $16 \mathrm{~mm}$. The region with max Mises stress was under the impactor, and because of rigid body of impactor, no stress contour was shown in impactor. The max stress was $2210 \mathrm{MPa}$, that the calculated results were in agreement with those of experiments.

For impact damage, sandwich composite displacement region that corresponding to the damage region as shown in figure 4, the max displacement offset of $0.5036 \mathrm{~cm}$, and the actual impact process medium pressure hole depth of $0.45 \mathrm{~cm}$, the error of $11.9 \%$.This error may be due to the simulation process, there is no other energy dissipation factors such as utility heat exchange in low-speed impact. Access to relevant data show that the finite element simulation of the impact damage sandwich materials, the calculation of the pit depth were higher than the actual impact crater depth, too.

Cellular sandwich composites after impact, the damage area of cellular continuous collapse to format debonding between the case and core material, cambium between crack. This study adopts zero thickness of cohesive element of unit to simulate the debonding behavior, and adopted as shown in table 2 and figure 2 constitutive relation to describe the mechanical behavior of cohesive force between surface and core. Interlayer stress along the $\mathrm{Z}$ axis direction (RF1) cloud picture as shown in figure 5, RF1 mainly appear in the impact point position and its nearby area, maximum stress appears at the point of impact. 
Interlayer stress caused by RF interlayer crack as shown in figure $5 \mathrm{~b}$, consistent with the actual cracking area.

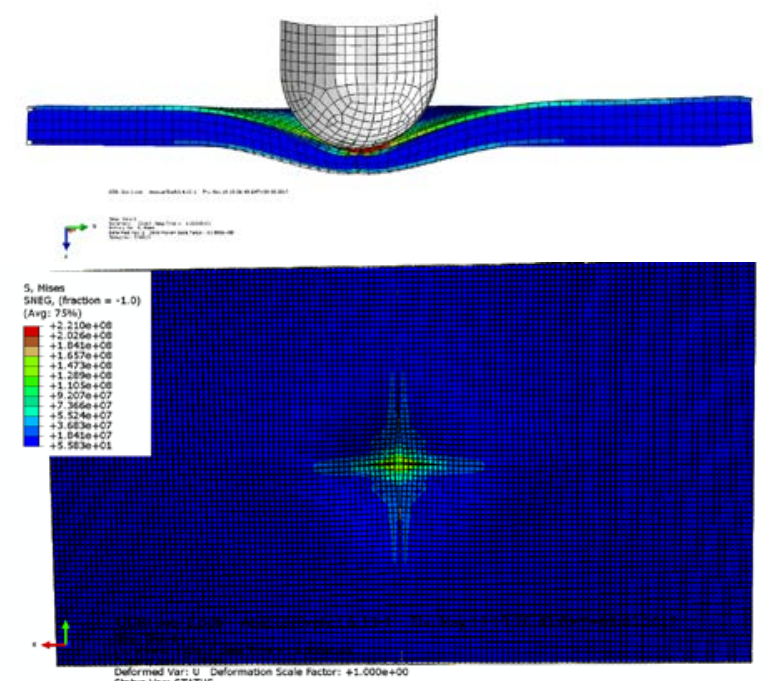

FIGURE III. THE MISES STRESS CONTOUR OF IMPACTED SANDWICH COMPOSITE

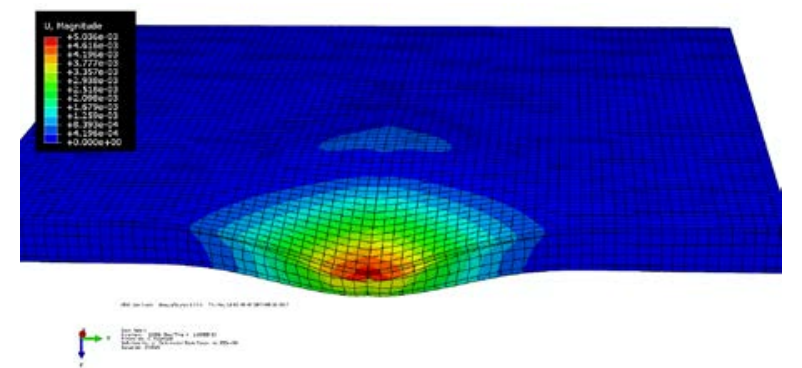

FIGURE IV. DISPLACEMENT CONTOUR OF IMPACT SANDWICH COMPOSITE

By Hashin criterion to judge the damage range and type of fiber reinforced composite panels, Hashin criterion defines four types of damage forms, respectively as the substrate tensile, compression matrix, and the fiber tensile and compression fracture. Abaqus numerical simulation provides the method of independent analysis of four types of fracture is using a predefined damage factors and damage parameter characterization of 4 types of injuries, including HSNMTCRT characterization of matrix under the load of axial tensile load and the ratio of tensile strength, when the damage factor $\mathrm{D}$ is greater than or equal to 1 , the material completely lose bearing capacity. Figure 6 for HSNMTCRT damage factor contours suggests that the matrix resin materials in the fiber reinforced composite panel in impact damage, tensile stress exceeds the tensile strength. Can be found from the figure 6 , the matrix resin material tensile damage range is very large, significantly greater than the actual observed pit. The cause of this phenomenon may be the actual observation, matrix resin micro cracks within a large area, part of the micro cracks area only by cutting the sample observation of the injury. While using Abaqus finite element simulation can reveal more microscopic deformation and stress characteristics. When a large number of micro cracks exist in the resin matrix, the general will lose bearing capacity.
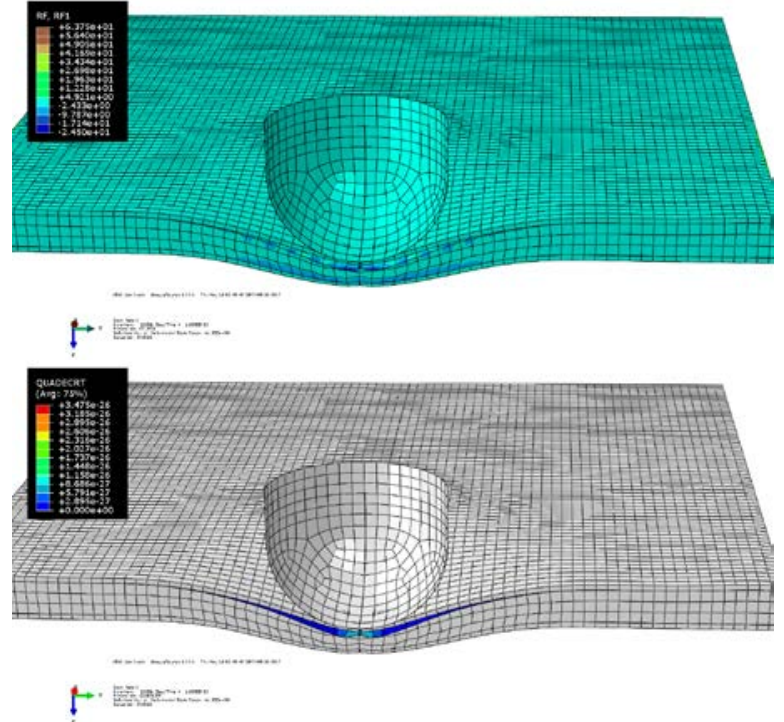

FIGURE V. STRESS CONTOURS OF INTERFACE COHESIVE ELEMENT AND DEBONDING REGION ON YZ PLANE

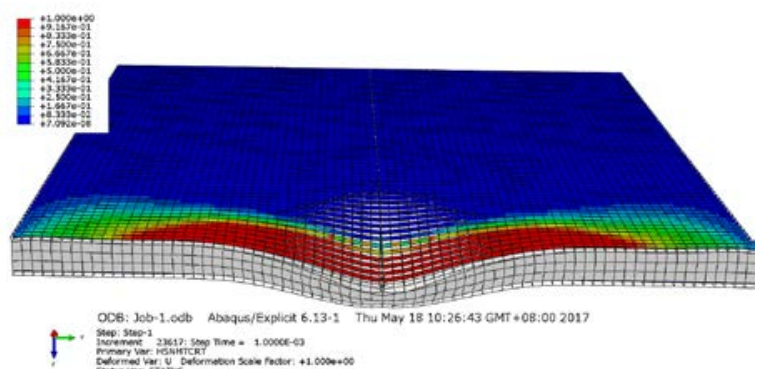

FIGURE VI. HSNMTCRT DAMAGE FACTOR CONTOURS OF THE SANDWICH COMPOSITE PLANE

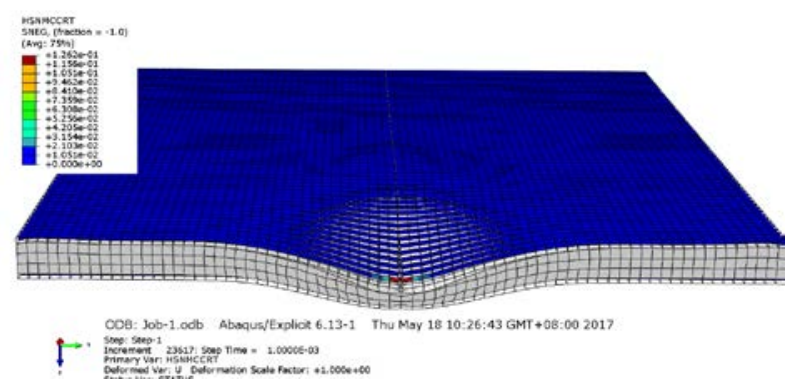

FIGURE VII. HSNMCCRT DAMAGE FACTOR CONTOURS OF THE SANDWICH COMPOSITE PLANE

Parameters HSNMCCRT characterization of matrix resin is in compression deformation damage parameters. This parameter using the same damage factor $\mathrm{D}$ to characterization of damage degree, and when the material on the maximum load is greater than the load limit, $\mathrm{D}$ is equal to 1 , indicate that completely lose bearing capacity. Figure 7 matrix resin compression deformation mainly occurred in a small area at the bottom of the head, other area due to the effect of constraints of the sandwich layer of small, mainly by tensile deformation.

HSNFCCRT characterization parameters pane fiber damage behavior of compression deformation and the damage factor cloud image is shown in figure 7.HSNFTCRT parameter 
characterization of panel fiber damage by tensile deformation behavior. Impact damage, fiber occurred damage of the matrix resin material. The compression injury mainly occurs in the head, and the tensile damage occurs mainly on the head curve of two side, the distribution is symmetrical.

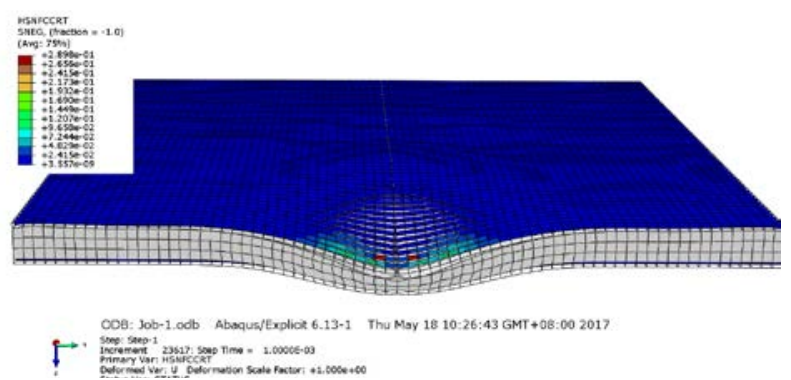

FIGURE VIII. HSNMCCRT DAMAGE FACTOR CONTOURS OF THE SANDWICH COMPOSITE PLANE

TABLE IV. COMPARED WITH THE SIMULATION RESULTS OF IMPACT INJURY

\begin{tabular}{|c|c|c|c|}
\hline & $\begin{array}{c}\text { Impact } \\
\text { Energy }\end{array}$ & $\begin{array}{c}\text { Depth of concave } \\
\text { (experiment) }\end{array}$ & $\begin{array}{c}\text { Depth of concave } \\
\text { (simulated) }\end{array}$ \\
\hline HKJ04-1 & 5 & 0.45 & 0.50 \\
\hline HKJ04-2 & 7.5 & 0.71 & 0.92 \\
\hline HKJ04-3 & 10 & 2.3 & 2.69 \\
\hline
\end{tabular}

Based on the different impact energy, the same layer distribution in the sample of indentation depth, and compared with simulation of demerit (simulation results, the value is the maximal displacement of impact point). Shown in the table below, the test result and simulation result of the error within $20 \%$.But in low energy impact, the simulation results with actual test pit depth of close to, but when increase the impact energy, the error of the widened gradually.Also simulated the impact of the damage is relatively large test results, may be due to the simulation process, regardless of the contact friction on the impact energy dissipation effect.

\section{CONCLUSIONS}

This study using Abaqus to establish a honeycomb sandwich composite material impact damage of threedimensional finite element model, using the stiffness degradation technology and improve the analysis of the Cohesive element damage failure behavior of honeycomb sandwich composite materials, the development of the honeycomb sandwich composite materials at low speed impact gradually damage prediction method and implementation process of sandwich composites in low speed impact injury of complete numerical simulation of the extended gradually under the impact load of damage by the final simulation results with the actual experimental results are in good agreement.

Prediction based on Hashin criterion of composite panel zone of injury, has realized the distribution of different types of damage prediction within the layer, the results showed that the substrate tensile damage as the main form of damage.
Sandwich composite low speed impact damage in the process of gradually expanding, before the punch up reach maximum damage area, in the process of the rise of the punch injury without extension, the formation of the damage is in the process of the punch down; Impact first occurred in the process of matrix cracking, delamination damage originating in matrix cracking, and the influence of the interlayer shear stresses on the delamination damage is very large.

\section{ACKNOWLEDGMENT}

The research described in this paper was supported by Natural Science Foundation of China U1633117. The authors acknowledge the financial assistance of civil aviation technology fundMHRD 20130203.

\section{REFERENCES}

[1] Thomsen OT. Sandwich materials for wind turbine blades - present and future. Journal of sandwich structure materials 2009, 11, 7 26.

[2] Greszczuck, L. B., Damage in Composite Panels due to Low Velocity Impact, Impact Dynamics, Z. A. Zukas (ed.), Wiley, 1982.

[3] J.Lee, C. Soutis. Prediction of Impact-Induced Fiber Damage in Circular Composite Plates. Applied Composite Materials. 2005 12: 109-131

[4] S. Abrate, J.F. Ferrero and P. Navarro. Cohesive zone models and impact damage predictions for composite structures. Meccanica 2015 50: 2587-2620

[5] Abrate S. Impact on composite structures. Cambridge: Cambridge UniversityPress; 1998

[6] Johnson AF. Modelling fabric reinforced composites under impact loads.Composites 2001;32:1197-206.

[7] Iannucci L, Dechaene R, Willows M, Degrieck J. A failure model for the analysisof thin woven glass composite structures under impact loadings. ComputStruct 2001;79(8):785-99.

[8] Hashin, Z.. Failure Criteria for Unidirectional Fiber Composites. Journal of Applied Mechanics,vol. 47, pp. 329-334, 1980

[9] Garnich MR, Akula VMK. Review of degradation models for progressive failureanalysis of fiber reinforced polymer composites. Appl Mech Rev2009;62:010801-10833.

[10] Palanivelu S, Van Paepegem W, Degrieck J et al, Numerical energy absorption study of composite tubes foraxial impact loadings. In: 17th international conference oncomposite materials (ICCM-17), Edinburgh, UK

[11] $\mathrm{Li}$ Chen. Interface and damage characterizations for Micro/Nanostructured Materials. Dissertation, University of Chinese Academy of Science. 2013 